\title{
Population Planning in Pakistan: Issues in Implementation and its Impact
}

\begin{abstract}
NAUSHIN MAHMOOD and SYED MUBASHIR ALI
It is over three decades now that we have official family planning programme in Pakistan. However, because of the absence of a coherent approach to overcome the social and cultural obstacles to the use of family planning in conjunction with poor service delivery and outreach activities; ineffective information, education and communication campaign; frequent changes in the organisational set up of the programme; inefficient management and lack of political commitment to family planning, the programme failed to achieve tangible success.

Nevertheless, recent demographic and fertility surveys indicated some positive changes in the demographic indicators. This suggest that the population programme may be in the right direction. In order to accelerate the pace of these changes, intensive and concerted efforts are needed.
\end{abstract}

\section{INTRODUCTION}

Population growth in Pakistan has shown continued increase since the 1940s due to reduced mortality and persistent high birth rates. The country's population grew from nearly 33 million in 1947 to about 135 million todate-an increase of over four times since the year of independence. Continued rapid growth in population has ranked Pakistan seventh in world and the third biggest contributor to world population growth. With a very young age structure, and a large number of people about to enter the reproductive years, the population has the potential to grow rapidly in the near future, even though fertility is expected to fall substantially.

High growth of population has been eroding Pakistan's economic and social progress during the past decades. The country still remains in the low income bracket with a per capita income of US $\$ 460$ and a literacy rate of about 39 percent, 50 percent for males and only 24 percent for females in 1996-97. The picture of reproductive and child health and provision of other social services is also not very encouraging. Only a third of women have access to a trained health worker during pregnancy and child birth, and family planning services reach only a quarter of the population. As such, Pakistan's fertility rate of 5.4 is considerably higher than that of any other large Asian country. The limited success in population planning programme and poor performance in other social sectors has placed Pakistan far behind many Asian countries on basic health and education indicators. The present situation warrants the immediate need to improve the

Naushin Mahmood is Chief of Research and Syed Mubashir Ali is Senior Research Demographer at the Pakistan Institute of Development Economics, Islamabad. 
population planning efforts and reduce the fertility rate drastically in order to cut down population pressures on country's physical and capital resources.

\section{POPULATION PLANNING PROGRAMME AND POLICIES-A BROAD VIEW}

Efforts to initiate population planning activities in order to regulate growth of population in Pakistan go as far back as the early 50s with the formation of the Family Planning Association of Pakistan (FPAP) in 1953, a non-government organisation (NGO). The Association worked entirely on its own until the government, realising the need for population planning, offered a small assistance of Rs 0.5 million to FPAP in its First Five Year Plan (1955-60). During this period, FPAP established clinics in selected cities and started providing family planning services.

An official programme of family planning was launched in 1960, when the policy-makers expressed their concern over the steadily increasing rate of population growth. During the Second Five-Year Plan (1960-65), population planning activities were officially initiated through the health sector with an allocation of Rs 15.5 million. At the end of 1964, there were 1589 family planning clinics functioning within the set up of health dispensaries, hospitals and maternal and child centres.' In addition, an independent Family Planning Council was constituted and a National Board of Family Planning was formed to advise the government on policy issues. The overall population policy recognised the need to change the attitudes of individuals towards small family size norms. An evaluation of the Second Plan revealed that the impact of the family planning programme was inadequate and much below expectations.

Following this, the government came forward boldly and introduced the first comprehensive and detailed national family planning scheme during the Third Five Year Plan (1965-70). An allocation of Rs 148 million was made with a target of providing family planning services to some 20 million couples in the entire country. For the execution of this programme, a total of 20,000 village 'dais' (Traditional Birth Attendants) were employed (one 'dai' for two villages), and about 1200 part time family planning doctors ( 6 for each tahsil) were registered and appointed for the purpose of IUD insertion and clinical sterilisation.

All these efforts were intended to bring down the crude birth rate from 50 to 40 per thousand population. Supply out-lets including private shops, pharmacies, clinics and health centres were established and supplied with all sorts of contraceptives at highly subsidised price.

The entire programme proceeded on the basis of statistical targets and estimated births averted. The programme started showing its weak impact and shortfall in the

\footnotetext{
'The programme was entirely clinic-based, with no motivational or follow-up service activity.
} 
targets that had been set too high without giving any attention to overcome social and cultural constraints. The services of 'dais' for outreach proved ineffective and controversial, and the impact of the programme was inadequate for achieving fertility reduction goals [Shah (1979)].

The results of the 1968-69 National Impact Survey (NIS) confirmed the apprehensions expressed by Robinson (1978) at the very beginning of the programme about its inefficacy and dismal performance. After 19 years of organised family planning efforts, supported by 14 years of active official support, only 6 percent of eligible couples were reported to be using contraceptives [TREC, (n.d.)]. It was realised that the weakest aspect of the effort so far had been the use of illiterate, poorly trained, part-time and low paid 'dais' for the implementation of the programme. However, success was noted in the spread of contraceptive knowledge as majority of married women were reported to have the knowledge of at least one method of family planning.

During the Fourth Five Year Plan (1970-75), a gradual replacement of 'dais' by a new category of full time family planning worker was envisaged to improve the effectiveness of services. For the implementation of the programme, the budget allocation was raised to Rs 315 million. Likewise, the target for birth prevention was raised from 3 million in the 3rd Plan to 9.6 million in the 4th Five Year Plan. It was presumed that by 1970 , about 18 percent of married women would be practicing contraception and this rate was expected to go up by 34 percent by the end of the plan period.

The implementation of the family planning programme in the initial years of the 4th Plan remained disrupted because of a series of political crisis in Pakistan including the war with India in 1971 and the separation of East Pakistan (which later became an independent country named Bangladesh). By 1973, normalcy had prevailed and the programme resumed.

Subsequently, the government introduced a new approach, the Continuous Motivation System (CMS) which tried to address the deficiencies of the earlier efforts by shifting the focus from target-oriented approach to client motivation and follow-up. In pursuance of this programme, teams of literate, married, male and female motivators were assigned to visit each operational unit with a target population of 8000 to 12000 persons to promote family planning, and distribute contraceptives. A family planning officer was made responsible for the work of six such teams and create massive demand for contraceptive knowledge. The CMS again was not fully implemented and had little impact as political interference in field workers recruitment and cultural hindrances did not let this approach to proceed with success.

To revitalise the programme, the government launched another strategy, the Contraceptive Inundation Scheme (CIS), which aimed at making contraceptives (condoms and orals) available to the entire population by putting supplies in every 
village and every quarter of urban areas through 50,000 shopkeepers and local agents as well as hospitals, clinics and full time motivators. Despite all efforts to increase the availability and supply of contraceptives, the programme fell short of its achievements and the acceptors did not surpass the levels estimated in the 1968-69 NIS. The results of the 1975 Pakistan Survey (PFS) revealed that the CPR was as low as 5.2 percent (see Table 1). By then, the population programme of Pakistan was rated as one of the least successful in the world [Robinson (1978)].

In 1977 , after the change in the political set up in the country, the programme met with severe criticism from the political and religious leaders, which led to the suspension of all programme activities until 1979. The shutdown of family planning activities was in line with the policy of "Islamisation" during that period which affected the functioning of the programme negatively.

The programme, during the Fifth Five Year Plan (1978-83) adopted a new multisectoral approach, emphasising linkages between health, population, nutrition, education and income in the development context. The population programme was transferred from the Ministry of Health to the Ministry of Planning and Development. Under this programme, the delivery of family planning services was one of several activities undertaken by Family Welfare Centres (FWCs). The programme, with its new name as the Population Welfare Plan, 1980-83, was restarted in the early 80s and was termed as the "New Beginning" in Pakistan's family planning programme [Robinson (1987)]. The reorganisation of the programme resulted in a reduction of staff (from 16000 to 8500 ), whereby field motivators were relieved of their jobs.

Table 1

Selected Indicators of Fertility and Contraceptive Use from Various Demographic Surveys in Pakistan, 1975-95

\begin{tabular}{lrrrrc}
\hline Indicators & $\begin{array}{c}1968-69 \\
\text { (NIS) }\end{array}$ & $\begin{array}{c}1974-75 \\
\text { (PFS) }\end{array}$ & $\begin{array}{c}1984-85 \\
\text { (PCPS) }\end{array}$ & $\begin{array}{c}1990-91 \\
\text { (PDHS) }\end{array}$ & $\begin{array}{c}1994-95 \\
\text { (PCPS) }\end{array}$ \\
\hline Crude Birth Rate & 39.0 & 40.5 & 36.6 & 35.0 & - \\
Children Ever Born & 4.2 & 4.3 & 4.3 & 4.1 & - \\
Total Fertility Rate & - & 6.3 & 6.0 & 5.4 & $5.4^{*}$ \\
Knowledge of & & & & & \\
$\quad$ Contraceptives & 97.0 & 75.6 & 61.5 & 77.9 & 90.7 \\
Ever Used Contraceptives & 12.5 & 10.5 & 11.8 & 20.7 & 28.0 \\
Current Contraceptive Use & 5.5 & 5.2 & 9.1 & 14.0 & $17.8^{* *}$ \\
Want No More Children & - & 49.4 & 43.4 & 36.4 & 52.0 \\
Infant Mortality & 121.0 & - & 106.0 & 91.0 & - \\
\hline
\end{tabular}

* 1993 Contraceptive Prevalence Survey.

** Based on currently married women only. 
Although an allocation of Rs 824 million was made during Fifth Plan period, (see Table 2), nothing tangible was accomplished during these years except for the restructuring and re-organisation of the programme. During the Sixth Five Year Plan (1983-88), the process of organisational changes continued. The field activities and provision of services were transferred to the provincial governments, while finance and policy-making was left with the federal government.

Table 2

ADP Allocations for the Population Welfare Programme and Actual Expenditures during Five-Year Plans; Pakistan: 1965-1998

\begin{tabular}{lccc} 
& & & (Rupees in Million) \\
\hline Plan Period & ADP Allocation & Actual Expenditure & $\begin{array}{c}\text { Percentage } \\
\text { Utilisation }\end{array}$ \\
\hline $\begin{array}{l}\text { Third Plan } \\
\text { (1965-70) }\end{array}$ & 148.200 & 167.714 & 113.167 \\
Fourth Plan & 1028.794 & 833.900 & 81.056 \\
$\begin{array}{l}\text { (1970-75) } \\
\text { Including 3 Years, i.e., }\end{array}$ & & & \\
1975-78 of Non-Plan Period & & & \\
Fifth Plan & 823.922 & 617.100 & 74.898 \\
$(1978-83)$ & & & \\
Sixth Plan & & & \\
$(1983-88)$ & 2044.300 & 1686.260 & 82.486 \\
Seventh Plan & & & - \\
$(1988-93)$ & $3535.000^{*}$ & 3046.900 & - \\
Eighth Plan & & & - \\
$1993-94$ & & & - \\
$1994-95$ & 1247.823 & NA & - \\
$1995-96$ & 1599.399 & NA & - \\
$1996-97$ & 1983.709 & NA & - \\
$1997-98$ & 2095.046 & NA & \\
Total (1993-98) & 2174.023 & NA & - \\
\hline
\end{tabular}

* Planned allocations. 
Two years after the start of this strategy, the results of the 1984-85 Pakistan Contraceptive Prevalence Survey (PCPS) indicated some improvement in the prevalence of contraception. The results showed that CPR was about 9 percent which again fell much short of official target of 19.4 percent set for the 5th Plan (see Table 3). However, the Pakistan Demographic Surveys (PDS) of 1984-87 diminished all hopes of achieving a success in the programme through reduced fertility and population growth rate, as their estimates indicated the crude birth rate at 43.3 per thousand and the total fertility rate (TFR) at 6.9 children per women [Government of Pakistan (1988)].

By the end of 7th Five Year Plan (1993), when the family planning programme in Pakistan had become 28 years old officially and 40 years old unofficially and had cost 6.35 billion rupees during the period, the contraceptive prevalence remained below 15 percent against the target set at 23.5 percent (see Table 3 ). However, the programme was successful in making family planning programme widely known to the people as knowledge of contraceptive increased upto 90 percent (see Table 1).

During the 1990s, government's strong and explicit support to family planning programme gave it a turning point. The results from the Pakistan Demographic and Health Survey of 1991 gave some encouraging news of a rise in contraceptive prevalence to 14 percent, but at the same time raised concern among public and policymakers about the low impact of the programme over a period of three decades.

In later years, indications of a rising trend in contraceptive use to nearly 18 percent in 1994-95 and to about 24 percent in 1996-97 [Ministry of Population Welfare/Population Council (1995); Hakim et al. (1998)] have shown signs of a positive response to the adoption of family planning among Pakistani couples. However, the question about the low impact of the programme still remains a matter of concern as only about a fifth of women in Pakistan are using contraceptives, despite investment of billion of rupees made during the past 30 years.

\section{Table 3}

Contraceptive Prevalence Rates (CPR): Five-Year Plan Targets and Achievements

\begin{tabular}{lcc}
\hline Five Year Plan Period & Plan Target & CPR: End of Plan Period \\
\hline Third Plan (1965-70) & - & $6.5 \%$ \\
Fourth Plan (1972-77) & - & $9.2 \%$ \\
Fifth Plan (1978-83) & $19.4 \%$ & $9.5 \%$ \\
Sixth Plan (1983-88) & $18.6 \%$ & $12.9 \%$ \\
Seventh Plan (1988-93) & $23.5 \%$ & $14.4 \%$ \\
Eighth Plan (1993-98) & $24.4 \%$ & $24.0 \%$ \\
\hline
\end{tabular}

Source:.NIPS, World Population Profile.

Government of Pakistan, Economic Surveys (Various Issues). 


\section{ISSUES IN IMPLEMENTATION AND ITS IMPACT}

The key issue for the progress of the population welfare programme is to improve coverage and accessibility to family planning services, and to meet the large unmet need that exists. Research studies on factors promoting small family norms and use of contraception suggest that knowledge of a source and an easy access to a service outlet are strongly related to contraceptive use for both urban and rural women [Mahmood and Ringheim (1996, 1997)]. These findings show that the programme has not reached a large proportion of couples and has failed to motivate those who have been reached. While 42 percent of wives and 63 percent of husbands reported knowledge of a family planning source, only 20 percent of women had easy access to a service outlet and 21 percent had heard a message through the media. It is continuously being argued that lack of success of population programme in Pakistan has largely been due to limited and inefficient supply of services [Ronbínson et al. (1981); Rukanuddin and Hardec-Cleaveland (1992); Mahmood and Ringheim (1996)]. However, it must be noted that in the process of expansion of services, and outreach, quality of service delivery needs special attention including follow up services to clients. In this context, some of the issues related to the implementation of the programme are discussed below.

\subsection{Weak Administration and Organisation}

An efficient and sound administrative and organisational infrastructure is considered an important component of a successful population programme [Bean and Meltzer (1968); UN/WHO (1969)]. Although a strong political support to the programme has been evident in all the development plans of Pakistan, the overall performance is marginal due to management problems. It was realised by the end of the third plan (1970) that population programme was administered under the control of civil servants who lacked the experience and technical know-how required to efficiently manage the programme. At the district level, the Deputy Commissioner was assigned the responsibility of controlling the programme administration, while he had other administrative functions to handle. This resulted in the neglect of his responsibilities for the programme and his duties became controversial in nature [Robinson (1978)].

In 1973, most of the civil servants, who by then were well experienced with the functioning of the family planning programme were replaced by ill-experienced noncivil service cadre, appointed on political grounds. At the grass root level too, most positions were filled on political grounds and on temporary basis. This created a noncoherence between political and non-political workers of the programme which resulted in a negative impact on programme implementation.

The organisational set up of the programme also kept shifting. In the early sixties, the family planning programme was set up within the Ministry of Health. Later 
on, the Population Welfare Programme was transferred to the Ministry of Planning and Development. The constantly shifting strategies and administration ruined the momentum built up every time. Moreover, experimentation with centralisation and decentralisation of programme activities has resulted in a conflict between the centre and the provinces about the division of responsibilities and accountability of the staff. While all policy decisions are taken at the federal level, implementation is carried out at the provincial level, creating confusions about the actual policy guidelines.

While the programme is federally financed, the service delivery is the responsibility of the provinces. This has created gaps and complications in personnel and financial matters. A discussion with Population Welfare Division personnel revealed that the funds allocated for the programme were often not disbursed in full. Moreover, at times, funds were sanctioned at inappropriate times resulting in uncoordinated efforts between various segments of the family planning programme. The underutilisation of funds allocated to the programme in the successive five year plans are reflected in Table 2. With the exception of third plan (1965-70), when more funds were expended than what had been allocated, all other allocations had a shortfall of utilisation.

Under the current organisational structure, all recruitments, promotions and transfers of personnel in provinces are managed at the federal level. This causes delay in filling up vacant and sanctioned positions, thereby affecting the timely implementation of programme activities.

\subsection{Poor Service Delivery and Outreach}

Critics of supply-oriented family planning programme are of the opinion that simply handing out contraceptives does not necessarily guarantee the practice of family planning [UN/WHO (1969); World Bank (1989) and Robinson (1978)]. In Pakistan, except for the Continuous Motivation System (CMS) approach, which was started to create a demand for family planning practice and was abandoned within two or three years after its promulgation, all other approaches were labelled as simply supply oriented [Robinson et al. (1981)].

In all those programmes, efficient distribution of contraceptive supplies was considered to be the key to the successful functioning of the programme. Such a responsibility was entrusted to the traditional 'dais' (birth attendants) who were mostly illiterate and saw this scheme against the interest of their profession. As a result, the objective of the programme was not achieved. After the failure of the CMS approach, a purely supply oriented scheme of contraceptive inundation was popularised. By the end of the 1970s, the findings of the 1979-80 Population, Labour Force and Migration (PLM) Survey indicated that 4 out of 5 women did not know where they could go to obtain a method and 85 in 100 women had never met any family planning personnel [Soomro and Ali (n.d.)]. 
It is on this premise that the multi-dimensional and multi-sectoral population welfare scheme was adopted in the 1980s. The Family Welfare Centres (FWCs), Mobile Service Units (MSU) and Reproductive Health Services (RHS) are the service delivery components of the Population Welfare Division (PWD). Service outlets of other ministries and departments, non-government organisations (NGOs), Hakeems and Homoeopaths, Traditional Birth Attendants (TBAs) and Registered Medical Practitioners (RMPs) are involved in motivating people and delivering services.

The FWC is the key service delivery component of the programme. Its multifaceted activities include family planning services, child care services, counselling and instruction on maternal and child health. TBAs also work under the supervision of FWCs and serve as village based contact for programme services. There are about 1356 FWCs located over the country (half of them in urban and semi urban areas). Each Centre is expected to cover about 20,000 to 30,000 population, which means that they could approximately cover less than one-third of the total population of the country. It has been estimated that the total coverage of the family planning programme did not exceed 25 percent of the population by the end of $1980 \mathrm{~s}$, and less than half of such achievements were attributed to the public sector [World Bank (1989)]. This supports the notion that the coverage of these centres has been far from satisfactory. Another inhibiting factor is difficulties in the physical accessibility of these centres. Distances range from an average of $9.3 \mathrm{k} . \mathrm{m}$. in Punjab to over $47 \mathrm{k} . \mathrm{m}$. in Balochistan [World Bank (1989)]. A small scale survey showed that awareness and use of FWCs diminishes correspondingly with increasing distance [Semple and Mitha (1986)].

The credibility of FWCs as a source of family planning or $\mathrm{MCH}$ outlet is also not yet established, as most of the clients come to these centres with general ailments considering it to be a centre of basic health services [World Bank (1989)]. According to an estimate, an average of about 2 or 3 clients per day visited these centres for family planning services [Population Welfare Division (1986)]. The findings of the 1990-91 Pakistan Demographic and Health Survey (PDHS) also confirmed the poor delivery services of FWCs, as only 13 percent of all contraceptives were reported to be supplied by these centres as compared to 50 percent by hospitals (Government or private) and 17 percent by drug stores and shops [Shah and Ali (1992)]. The overall performance of family planning service delivery remained short of the targets as 28 percent of the demand remained un-met, according to the results of the PDHS [Ali and Rukanudin (1992)].

At present, some 5000 TBAs are formally associated with the population programme. Recognising their importance as a strong channel for messages about family planning, their number increased to 7000 in the Eighth Plan. However, a study based on TBAs training for family planning showed that half of them did feel that working for family planning would interfere with their profession, whereas one-third 
considered family planning against their profession. [Ahmed (1971)]. It is argued that a TBA is only a part time worker for an amount as meager as Rs 100.00 per month, ${ }^{2}$ the family planning objectives can not be accomplished unless her income from births prevented outweighs her dividends from deliveries conducted. The finding of 1990-91 PDHS confirmed this argument as only 1 percent of the current users were either provided contraceptive methods or given information about the supply source of contraceptive methods by them [Shah and Ali (1992)].

\subsection{Faulty Evaluation of the Programme}

The population programme has no built-in evaluation system and depends largely on the results of sample surveys conducted 5 to 7 years apart. According to Ahmed (1971) "sample surveys can provide information about the appropriateness of the programme in a specific community or district; they cannot measure the achievements of programme functionaries or identify problems of local importance". On the other hand, service statistics, which are based on the sale and distribution of contraceptives are found to be inadequate to establish the success of the programme.

\subsection{Training of the Programme and Non-programme Personnel}

The failures in the implementation of the past programmes are argued on account of poor training of the programme personnel particularly of the grass-root workers. For example, the TBAs were severely criticised for not even knowing the basic information about family planning methods. CMS workers were also found to be deficient in performing their prescribed duties including maintenance of registers and record keeping.

The multi-sectoral strategy of the programme initiated in the 7th Five Year Plan, required family planning and non-family planning programme workers to be coordinating and interacting well in terms of their duties and responsibilities. Apparently, the training of clinical personnel within and outside the family planning programme through 12 Regional Training Institutes (RTIs) followed by refresher courses have shown impressive outcome. In addition, a relatively better performance of RHCS where such workers are mostly deputed speaks of its accomplishments. However, poor performance of FWCs in terms of imparting knowledge among the masses about the multi-faceted activities of these centres could be due to the poor training of the workers stationed in these centres. Recently, field visits of $646 \mathrm{FWCs}$ have shown that about half of FWCs visited had blank or incomplete client address registers, and a fifth of FWCs had no sign boards to guide potential clients to the outlet. All such deficiencies in the functioning of service outlets badly affects the implementation and achievement of targets.

${ }^{2}$ In the Eighth Five-Year Plan, TBAs wage has been increased to Rs 200 per month. 


\subsection{Information, Education, and Communication (IEC)}

The IEC activities have been instrumental in raising awareness and knowledge about the programme, and population issues, but remained ineffective to bridge the gap between the knowledge and practice of family planning. Moreover, the communication strategies and messages overlooked an important aspect of providing information to the people about places where services were available. One of the major reasons for the non-practice of family planning methods is the fear of side effects. The IEC activities have not been effective enough to remove the fear of side effects of family planning methods among a substantial number of clients. Such campaign could be more effective if supported by information about where services could be obtained and how much safe they could be. The IEC campaigns have not adequately informed people about the range of available methods and actions that can be taken to obtain them [Rosen and Conly (1996)]. It is suggested that a less centralised IEC system, staffed by trained employees, with an active evaluation system could increase the effectiveness of family planning programme [World Bank (1989)].

\subsection{Poor and Inadequate Logistics}

Placement and distribution of contraceptives remained the responsibility of federal government. This created supply problems and stock out of contraceptives at various regional levels. The 1984-85 PCPS found that 14 percent of dropouts were caused by lack of supplies at FWCs. An evaluation survey report of FWCs revealed that in 16 out of 27 months, FWC stocks of condoms were not sufficient to last one month. Likewise, injectable were found to be sufficient in 13 out of 27 months. Overall, only 20 percent of the FWCs were found to be sufficient in all items [PWD (1986)].

The effectiveness of MSUs in the diffusion of contraception was rated as good but due to limited number of such units, their outreach capacity could not expand.

\section{RECENT INITIATIVES}

The need for accelerating population programme activities was emphasised further in the current development plan in the wake of the fastly growing population with a small impact of the programme on raising the level of contraceptive use and reducing family size. It was in the backdrop of this realisation that Pakistan's government launched a multi-sectoral Social Action Programme (SAP) in 1993 with multi-billion investment in social sectors with special emphasis on health and population programme. The strategy of SAP initiatives is to be implemented by the provincial governments with involvement of community, NGOs and private sector. Later on, SAP objectives were integrated into strategies and actions of the Eighth Five Year Plan (1993-98). The activities taken by SAP focus on improving the quality of services, particularly in rural areas, increasing access to family planning through social 
marketing and Ministry of Health outlets and increasing demand for family planning through information and media programmes.

The Eighth Five Year Plan aims at raising contraceptive prevalence rate from 14.0 to 24.4 percent (Table 3 ) by increasing the overall coverage of family planning services from 20 percent to 80 percent, and reducing the total fertility rate from 5.9 to 5.4 percent.

To accelerate the programme activities in all geographical areas, the strategy in rural areas is to increase the number of Family Welfare Centres (FWC), Reproductive Health Centres (RHC), Mobile Service Units (MSU) and Traditional Birth Attendants. In addition a community based network of Village Based Family Planning Workers (VBFPW) and Lady Health Workers (LHW) is operative to act as motivators-cumproviders in village serving population of 1500 and above in each community.

The strategy in urban areas is to increase the number of Family Welfare Centres, Reproductive Health Centres, Target Group Institutions and private hospitals in dispensing family planning services. In addition, involvement of registered medical practitioners, hakeems, and homeopaths in providing clinical and non-clinical methods is also expanded. The basic aim is to expand family planning services network in the public sector with active involvement of NGOs and the communities.

Various demographic and fertility surveys suggest some notable changes in the demographic indicators since the 1990s. This suggests that population planning programme in Pakistan appears to moving in the positive direction, but these efforts will take time to bear desired result as substantial problems in management, and service delivery and outreach continue to affect programme's implementation and its impact.

\section{CONCLUSION}

The official population programme in Pakistan has a history of about 30 years having started as part of a health programme in the 1960s, then shifting to the Ministry of Planning and Development in the 1980s, and then becoming an independent portfolio under the umbrella of the Ministry of Population Welfare in the early 1990s. During all these years, the programme has been subjected to various organisational changes and shifts in strategies without earlier activities having been fully implemented, as well as inconsistent political commitment and support for the execution of programme.

Since the inception of the population programme in the Second Plan period (1960-65), about 9 billion rupees have been spent on it without showing any significant impact on reducing fertility levels and population growth rate, which is one of the main objectives of the programme. This has been mainly because of the absence of a coherent approach to overcome the social and cultural obstacles to the use of family planning in conjunction with popularising supply strategies and schemes, inefficient management and lack of political commitment to family planning. 
Since the 1990s, however, the population programme has showed some positive change in contraceptive prevalence and total fertility rate, even though the progress has been slow to show any substantial gains. For example, in terms of service availability, only about a quarter of population has easy access to a family planning service outlet, and only a third of women have access to services of trained health worker during pregnancy and child birth.

Currently, the government's renewed commitment to the population programme in terms of its increased political, financial and administrative support backed with initiatives to intensify and expand coverage and outreach has raised some hope. The prospects for future success in population programme depend largely on continued and sustained programme strategies, efficient management, heightened political commitment and fundamental changes in people's attitudes towards family planning. To achieve this, massive and intensive efforts are needed to make up for the past failure and lost time.

\section{REFERENCES}

Ahmed, Wajihuddin (1971) Field Structure in Family Planning. Studies in Family Planning 2:1.

Ali, S. Mubashir, and R. Rukanuddin (1992) Family Size Preferences in Pakistan

Demographic and Health Survey 1990-91. Islamabad: National Institute of Population Studies/DHD/RD/Macro International Inc.

Bean, Lee L., and William Meltzer (1968) Couple Years of Protection and Birth Prevented: A Methodological Examination. Demography 5:2.

Family Planning Council (1965) Family Planning Scheme for Pakistan during the Third Five-Year Plan (1965-70). Islamabad: Ministry of Health, Labour and Social Welfare.

Hakim, Abdul, John Cleland, and Mansoor ul Haq (1998) Pakistan Fertility and Family Planning 1996-97. Islamabad: National Institute of Population Studies.

Mahmood, Naushin, and Karim Ringheim (1996) Factors Affecting Contraceptive Use in Pakistan. The Pakistan Development Review 35:1 1-22.

Mahmood, Naushin, and Karim Ringheim (1997) Knowledge, Approval and Communication about Family Planning as Correlates of Desired Fertility among Spouses in Pakistan. International Family Planning Perspectives 23:3.

Pakistan, Government of (1965) Third Five-Year Plan 1965-70. Islamabad: Planning Commission.

Pakistan, Government of (1986) Pakistan Contraceptive Prevalence Survey 1984-85. Islamabad: Population Welfare Division.

Pakistan, Government of (1988) Pakistan Demographic Survey 1987. Karachi: Federal Bureau of Statistics. 
Pakistan, Government of (1993) Eighth Five-Year Plan 1993-98. Islamabad: Planning Commission.

Pakistan, Government of (1995) Pakistan Contraceptive Prevalence Survey 1994-95, Basic Findings. Islamabad: Ministry of Population Welfare/The Population Council. Population Welfare Division (PWD) (1986) Pakistan Contraceptive Prevalence Survey 1984-85. Islamabad: Population Welfare Division.

Robinson, W. C. et al. (1981) The Family Planning Programme in Pakistan: What Went Wrong. International Family Planning Perspectives 7:3.

Robinson, Warren C. (1978) Family Planning in Pakistan 1955-77-A Review. The Pakistan Development Review 17:2 255-281.

Robinson, Warren (1987) The New Beginning in Pakistan's Family Planning. The Pakistan Development Review 26:1 107-118.

Rosen, James E., and Shanti R. Conly (1996) Pakistan's Population Programme: The Challenge Ahead. Washington, D. C.: Population Action International.

Rukanuddin, Abdul Razzaque, and Karen Hardee-Cleavland (1992) Can Family Planning Succeed in Pakistan. International Family Planning Perspectives 18:3.

Semple, Michael, and Yameena Mitha (1986) Evaluation of the Outreach Component in the Family Welfare Centres in Pakistan-A Report of the Pilot Project in Rawalpindi District. NIPS, Islamabad.

Shah, Nasira M. (1979) Past and Current Contraceptive Use in Pakistan. Studies in Family Planning 10:5.

Shah, Nasra, and S. Mubashir Ali (1992) Knowledge and Use of Family Planning. National Institute of Population Studies, Macro Int. (PDHS Report 1991.)

Soomro, Ghulam Yasin, and S. Mubashir Ali (n.d.) Prevalence of Knowledge and Use of Contraceptives in Pakistan. Pakistan Institute Development Economics, Islamabad. (PLM Report No. 3.)

Training Research and Evaluation Centre (TREC) (n.d.) National Impact Survey Report. Lahore.

United Nations: WHO (1969) Pakistan: Report on the Family Planning Programme by the UN, WHO Advisory Mission. Studies in Family Planning 40.

World Bank (1989) Rapid Growth in Pakistan: Concerns and Consequences. Washington, D.C.: The World Bank. 